\title{
E yacimiento de ámbar cretácico de Peñacerrada (Álava) \\ Una extraordinaria puerta de acceso al Aptiense (112-114 m.a.)
}

Jesús Alonso

Director del Museo de Ciencias Naturales de Álava
A finales de la década de los 80, el Museo de Ciencias Naturales de Álava (MCNA) financia la prospección y recolección sistemática de rocas mesozoicas en la provincia de Álava. El objetivo, la configuración de sendas colecciones científicas de referencia, que sirviesen como material práctico en el desarrollo de los Cursos de Reconocimiento Petrográfico, que por aquel entonces el MCNA ofertaba, fundamentalmente, a profesores de Enseñanzas Medias.

Consecuencia de aquellas recolecciones se dan de alta en el museo las primeras piezas de ámbar, que con los números de inventario MCNA 386 y MCNA 387 de la Col. Mineralógica, y MCNA 190.I, MCNA 190.2, MCNA 191.I y MCNA 191.2 de la Col. Petrológica, constituyen las primeras citas de ámbar mesozoico para el País Vasco.

El avanzado estado de alteración presente en aquellas primeras muestras, recogidas en superficie, impedía realizar cualquier valoración relativa al contenido de inclusiones biológicas en su interior. Cierto es, igualmente, que nadie pensó entonces seriamente en dicha posibilidad.

Es a principios de los años 90 cuando la creación en Vitoria de la Asociación Gemológica Vasca y la posterior puesta en marcha por ésta de los Cursos de Gemología, trae como consecuencia la generación de sucesivas promociones de gemólogos que prospectan el territorio en busca de materiales susceptibles de ser tallados.

En 1995, el gemólogo Rafael López Del Valle, procedente de la segunda promoción de gemólogos de la citada escuela, tropieza con las primeras inclusiones de insectos, como consecuencia del tallado y pulido sistemático del ámbar procedente de sus recolecciones. Consciente de la relevancia del hallazgo se pone en contacto con el MCNA, quien a partir de este momento procede a una intensa campaña de campo con el fin de valorar los indicios existentes y tratar de delimitar la distribución y potencialidad del yacimiento.
Se realizan los primeros desbroces y calicatas en la primavera de 1995 y se inicia la cartografía geológica a escala 1:5.000 de los aproximadamente 100 $\mathrm{km}^{2}$ comprendidos entre los Puertos de Herrera y Rivas de Tereso, en las vertientes norte de la Sierra de Cantabria. La complejidad estructural de esta zona, acentuada por importantes intrusiones diapíricas, y el desarrollo de potentes suelos forestales bajo robledales y hayedos, dificulta enormemente la localización de afloramientos y la comprensión y modelización tridimensional del yacimiento. No obstante, la aparición de nuevos indicios va sucediéndose a lo largo de año y medio de intenso trabajo de campo. A finales de 1997, las hipótesis relativas a la importante distribución lateral del yacimiento son ya una certeza.

Paralelamente a los trabajos de campo, se inician los trabajos de prospección en laboratorio de las inclusiones biológicas atrapadas en el ámbar, procedente de los sucesivos indicios que día a día van apareciendo. Se procede igualmente a la definición técnica de los protocolos necesarios para la correcta manipulación y tratamiento de los materiales rescatados. Es el geólogo José Carmelo Corral, especialista en el tratamiento y conservación de colecciones geológicas, quien a partir de ese momento se responsabiliza de la definición de dichos protocolos y de su correcta aplicación a los materiales que, día a día, van ampliando el fondo existente.

A lo largo de 1996 se comienza a configurar lo que ha de ser el núcleo central del equipo de investigación para el ámbar de Peñacerrada. Se envían las primeras muestras al Dr. Joan O. Grimalt (CSIC) para proceder a la caracterización química del ámbar. Se contacta igualmente con el Paleobotánico Dr. Eduardo Barrón, quien realiza las primeras columnas palinológicas y las primeras dataciones cronológicas de las capas negras, portadoras del ámbar, a partir de su análisis polínico.

En lo relativo al estudio sistemático y taxonómico de las inclusiones, el MCNA contacta con los docto- 
Ciertamente, estamos ante una magnífica puerta de acceso al pasado. Los grandes volúmenes de información relativa a los procesos biológicos y geológicos del periodo que denominamos Aptiense, se encuentran tras ella. Debemos considerar este hallazgo como un auténtico regalo de conocimiento $y_{1}$ entender por tanto, la importante responsabilidad de su adecuada gestión patrimonial, científica y cultural. Es nuestra directa responsabilidad pero, como conocimiento, patrimonio de la humanidad.

res Antonio Arillo, Xavier Martínez Delclós y Vicente Ortuño, para los grupos de dípteros, himenópteros y miscelánea respectivamente.

En los laboratorios del museo, el trabajo conjunto del geólogo José Carmelo Corral y del gemólogo Rafael López Del Valle, relativo a la manipulación, prospección de inclusiones y preparación de las mismas, comienza a generar un flujo significativo de taxones hacia los especialistas citados. A finales de 1996, el número de inclusiones detectadas supera el medio millar.

En este estado de cosas, se inicia el año 1997 con dos objetivos fundamentales: la protección tanto física como jurídica de los indicios con mayor riesgo de depredación, y la organización de un congreso internacional sobre inclusiones en ámbar. La presentación a la comunidad científica internacional del yacimiento alavés, la definición de su peso específico como fondo de conocimiento, la puesta en común de las últimas técnicas de tratamiento y conservación del ámbar, así como los últimos resultados en la investigación de inclusiones biológicas, fueron los objetivos predefinidos por la organización para este congreso que, bajo la denominación World Congress on Amber Inclusions -Congreso Mundial sobre Inclusiones en Ámbar- Anbarreko Inklusioei Buruzko Nazioarteko Biltzarra, se celebró en Vitoria-Gasteiz los días 20 a 23 de octubre de 1998. Durante estos cuatro días se realizaron 63 comunicaciones, estructuradas en 7 sesiones generales, a las que asistieron 130 congresistas procedentes de 13 países. Los objetivos prefijados por el Comité Organizador fueron plenamente cubiertos, tanto en los niveles de comunicación científica como en el análisis de los intereses de organizaciones y personas vinculadas a la investigación del ámbar y sus inclusiones.

En lo relativo a la protección física, el MCNA diseña una intervención para el yacimiento de Peñacerrada I (uno de los indicios más evidentes y con mayor peligro potencial de depredación, dada su proximidad a una vía de comunicación) consistente en el rescate de las capas negras que afloraban en superficie. Se extrajeron 25 metros cúbicos aproximadamente de las citadas capas, que tras su disgregación y lavado aportaron unos 40 kilos de ámbar. Una vez finalizada la intervención, se procedió a la cubrición preventiva del yacimiento, a su cercado y a su señalización.

Los consiguientes trabajos de laboratorio habían proporcionado ya, a finales del año 1997, más de un millar de inclusiones biológicas.

En lo relativo a su protección jurídica, el Departamento de Cultura y Euskera de la Diputación Foral de Álava, en cumplimiento de sus responsabilidades en materia de Patrimonio Cultural del Territorio Histórico de Álava y, a tenor de lo dispuesto en la Ley de Patrimonio Cultural Vasco, solicitó la incoación del correspondiente expediente de calificación ante los Servicios Técnicos del Centro de Patrimonio Cultural del Gobierno Vasco.

Visto el interés científico, cultural y patrimonial que representa el ámbar del yacimiento de Peñacerrada, y atendiendo a la propuesta de resolución presentada por los Servicios Técnicos del citado Centro de Patrimonio Cultural, el Viceconsejero de Cultura del Gobierno Vasco decide proceder a la incoación del correspondiente expediente de calificación, en resolución de 30 de marzo de 1998, otorgando al yacimiento de Peñacerrada la máxima protección jurídica marcada por la ley, esto es, la de "Bien Cultural Catalogado".

Dicho expediente de calificación es sometido a información pública en el Boletín Oficial del País Vasco No 109 de 12 de junio de 1998. No presentándose alegaciones al mismo, prosigue su tramitación. Es en Consejo de Gobierno de 15 de septiembre de 1998 cuando se procede a la aprobación definitiva de la calificación solicitada para el yacimiento de Peñacerrada, siendo publicado el correspondiente Decreto 230/98 en el Boletín Oficial del País Vasco N 187 de fecha I de octubre de 1998. 

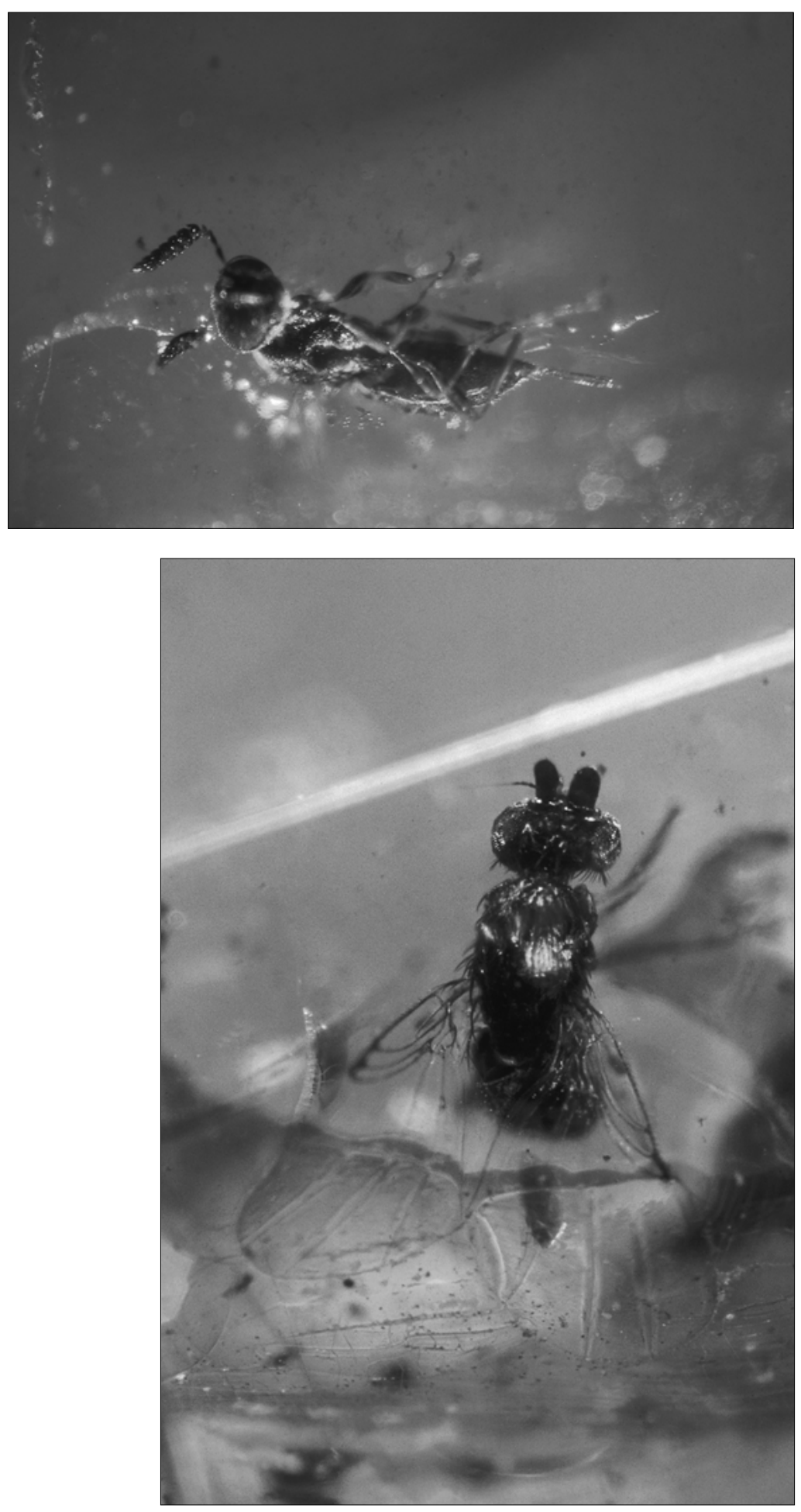

I. Himenóptero de la familia de los Scelionidos (Foto: Rafael López)

2. Díptero de la familia de los Fóridos. Desde su hallazgo en el ámbar de Peñacerrada, es la mosca verdadera más antigua que se conoce (Foto: Carlos Hermosilla)

El yacimiento de ámbar de Peñacerrada es el primer yacimiento paleontológico al que se le otorga la calificación de "Bien Cultural Catalogado", al amparo de la Ley de Patrimonio Cultural Vasco.

Incluyendo el yacimiento de Peñacerrada, no hay más de veinte localidades en todo el planeta en las que se haya citado ámbar con inclusiones biológicas. Pero de ellas, tan sólo cuatro presentan una edad superior a los noventa y cinco millones de años, es decir, tan sólo cuatro sobrepasan el límite entre el Cretácico Superior y el Inferior.

La singularidad del yacimiento alavés radica en su edad, ya que es el único yacimiento de ámbar conocido de edad Aptiense Superior, es decir, caracteriza el periodo de tiempo comprendido entre los 112 II 4 millones de años.

Otra singularidad presente en el yacimiento de Peñacerrada es el altísimo número de inclusiones biológicas (sólo superada en estos momentos por la suma de las aparecidas en los yacimientos de Líbano, Jordania e Israel). En tres años de intenso trabajo, el MCNA ha aislado más de 1500 inclusiones biológicas, lo que nos permite afirmar desde un punto de vista estadístico, y a tenor del volumen de material que aún queda por valorar, que el yacimiento alavés es el más rico en inclusiones de cuantos se conocen para el Cretácico Inferior.

También es alto el número de grupos de organismos diferentes atrapados en las resinas fósiles de Peñacerrada. Hasta la fecha han aparecido trece órdenes distintos en lo que a insectos se refiere, además de plantas, hongos, bacterias, moluscos, crustáceos, arácnidos, plumas de aves, etc.

Téngase en cuenta que la mayoría de los taxones aparecidos hasta la fecha en nuestros materiales, son los más antiguos conocidos en el registro fósil del planeta para sus respectivos grupos filogenéticos, lo que permitirá completar los cimientos de los árboles evolutivos de un alto número de grupos biológicos. Aparecen igualmente los últimos representantes de grupos que no tienen representación en las faunas modernas de insectos, al no sobrepasar el límite Cretácico Superior - Cretácico Inferior.

El yacimiento de Peñacerrada se tipifica en terminología científica como Konservation Lagerstätte. El término se aplica a aquellos yacimientos paleontológicos con características excepcionales de fosilización, por ejemplo, la conservación de partes blandas. En la actualidad, el número de yacimientos así tipificados no supera la veintena en todo el mundo, lo que nos da una idea del valor potencial de este tipo de yacimientos como fuente de información sobre la vida y sus condicionantes en épocas remotas del planeta. Ciertamente, estamos ante una magnífica puerta de acceso al pasado. Los grandes volúmenes de información relativa a los procesos biológicos y geológicos del periodo que denominamos Aptiense, se encuentran tras ella. Debemos considerar este hallazgo como un auténtico regalo de conocimiento $y$, entender por tanto, la importante responsabilidad de su adecuada gestión patrimonial, científica y cultural. Es nuestra directa responsabilidad pero, como conocimiento, patrimonio de la humanidad. 
A lo largo de 1998, el equipo investigador, al que se incorpora el físico Dr. Rubén Cerdán, concreta sendos proyectos de investigación relativos a la sistemática y taxonomía de las inclusiones biológicas, a la definición y estudio físico-químico de las inclusiones no biológicas, a la caracterización química estricta del ámbar de Peñacerrada, y a la caracterización estratigráfica y estructural de los yacimientos de ámbar. Todos ellos, concretados bajo la denominación genérica Proyecto Ámbar-2000, son dirigidos y coordinados por el Museo de Ciencias Naturales de Álava. El cronograma del citado proyecto posiciona las diversas tareas de los cuatro aspectos generales señalados, a lo largo de los dos próximos años.

Señalamos a continuación una breve síntesis de los cuatro aspectos abordados por el citado proyecto.

\section{Aspectos sistemáticos y taxonómicos}

El ámbar de Peñacerrada contiene, como ya se ha mencionado, una fauna y flora diversificada, que viviría en bosques de araucariáceas a finales del Cretácico Inferior, en la región que actualmente ocupa la provincia de Álava.

Los insectos son un grupo de organismos que tienen bastantes dificultades de conservación en el registro fósil a causa de su cuerpo blando. Los yacimientos de fósiles donde estos insectos aparecen - generalmente asociados a arácnidos y crustáceosson raros debido a las excepcionales condiciones tafonómicas necesarias para su preservación. Es el caso del ámbar, que preserva el exoesqueleto de un gran número de estos organismos de manera casi perfecta. Además, el ámbar preserva insectos de pequeño tamaño, que raramente aparecen en los yacimientos de compresión (Calizas, carbones, arcillas, etc.).

La edad y el emplazamiento del yacimiento de Peñacerrada son muy importantes para comparar las faunas de insectos antiguas (Jurásico-Cretácico inferior) con agrupaciones más parecidas a las modernas (Cretácico superior-Actual). En este yacimiento se pueden observar familias antiguas en coexistencia con individuos de familias actuales, y familias completamente extinguidas, en coevolución con plantas antiguas y angiospermas.

Es también importante el estudio de los insectos de Peñacerrada sobre la base de los estudios de distribución paleogeográfica, después de la práctica total fragmentación de Pangea.

\section{Aspectos físico-químicos}

La completa caracterización del ámbar, tanto a nivel químico como físico, pretende obtener datos precisos acerca de los procesos diagenéticos, polimerización y procesos de envejecimiento que afectan a la resina fósil. Dichos datos serán de utilidad en la comprensión de las complejas interacciones que se dan entre el tejido vivo y la resina.

Se pretende abordar igualmente, al amparo de las actuales técnicas analíticas, la composición de la paleoatmósfera, lo que requerirá la extracción del gas encerrado en microburbujas, así como la cuantificación de las concentraciones de diversos elementos. Estas actividades se orientan a la verificación crítica de las hipótesis actuales que postulan la existencia de un aumento en los niveles de oxígeno y dióxido de carbono atmosféricos durante el Cretácico. También se abordarán las tareas relativas a la modelización de la paleoatmósfera y sus implicaciones en lo concerniente a las intensidades de las radiaciones UVA y UVB que cabría esperar en tal escenario. Téngase en cuenta que los efectos mutagénicos inducidos por la radiación ultravioleta en
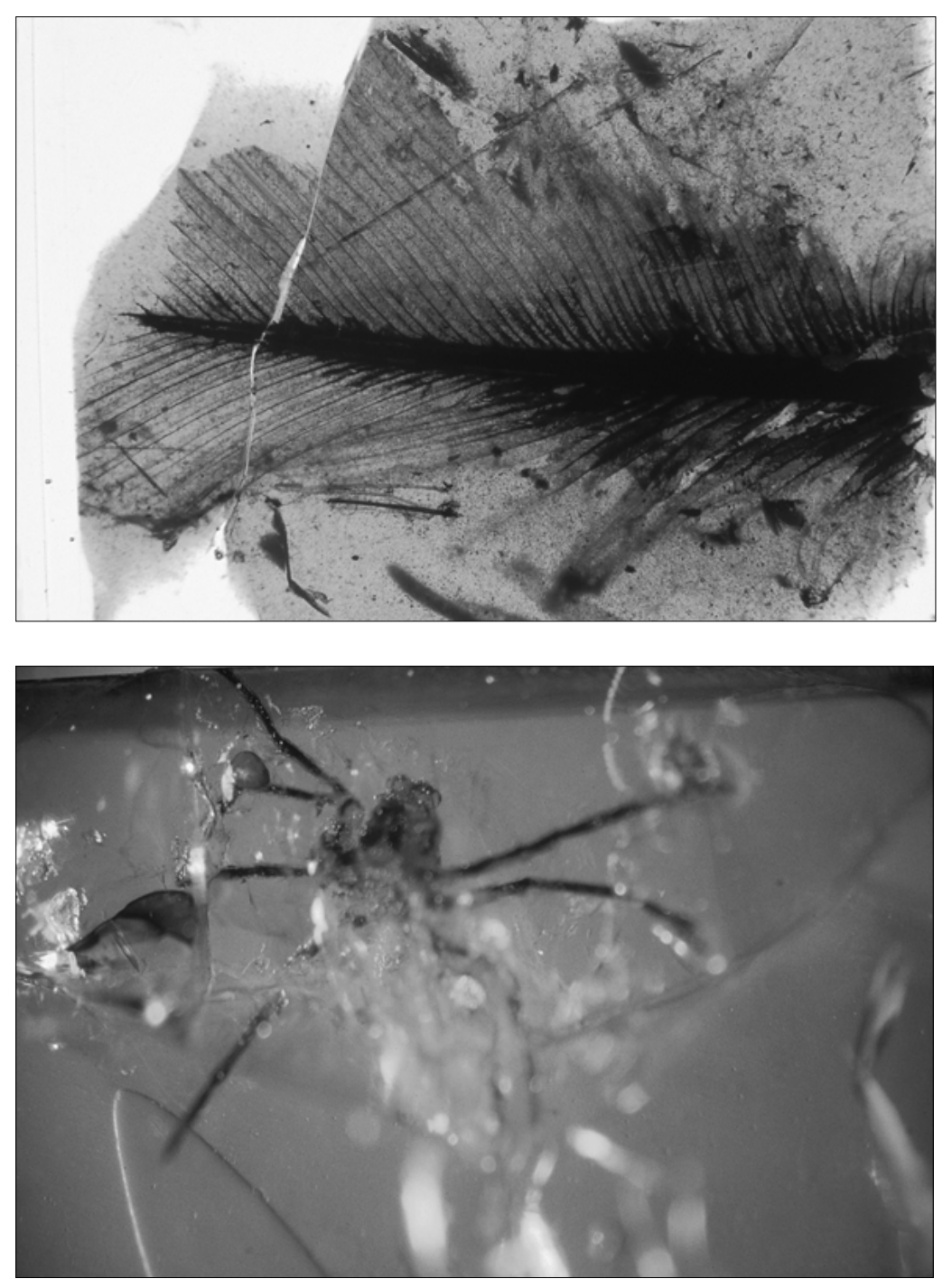

3. Fragmento de pluma. Con un raquis fuerte y barbas perfectamente definidas, su propietario estaba capacitado para el vuelo (Foto: Rafael López)

4. Vista ventral de uno de los numerosos arácnidos aparecidos hasta el momento. Los movimientos para liberarse de la resina produjeron numerosas burbujas de aire, que también han quedado fosilizadas (Foto: Rafael López) 


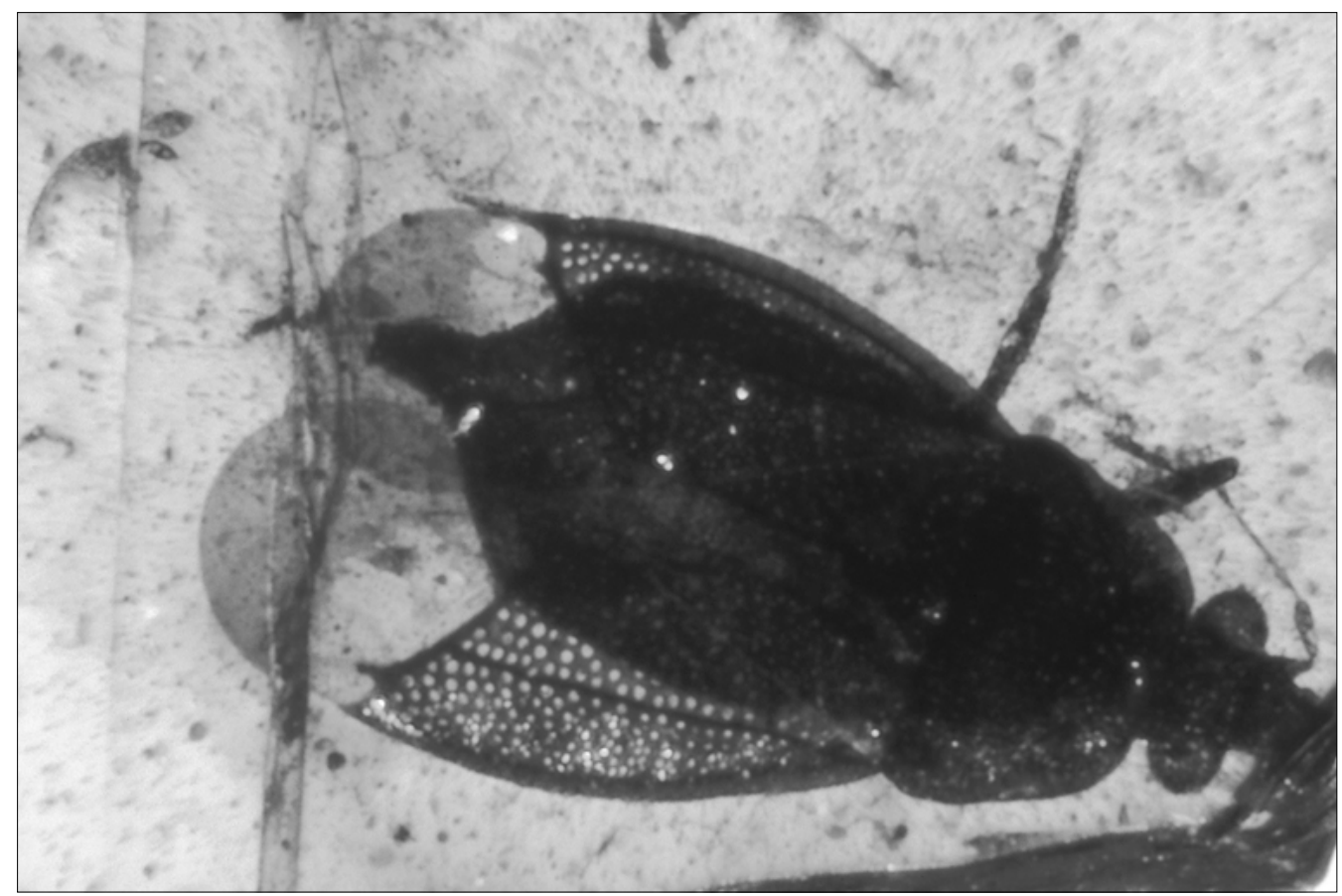

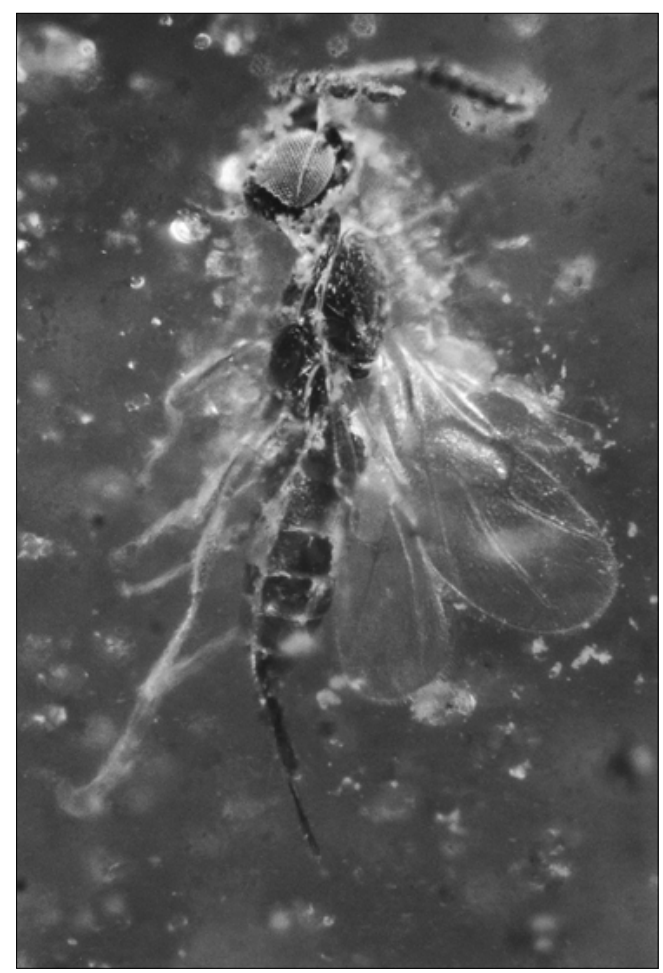

5. Heteróptero (chinche) de la familia de los Antocóridos. Se observan bien las alas interiores sobresaliendo bajo los elitros (Foto: Rafael López)

6. Atractivo ejemplar de heminóptero, de la familia de los Sceliónidos. Fue uno de los primeros ejemplares en aparecer (Foto: Enrique Peñalver)

presencia de un exceso de oxígeno, deben tener su observable en una tasa de mutación anormalmente alta en aquellos genes homeóticos específicos que pudieran recuperarse de los fragmentos de ADN procedente de las inclusiones biológicas del ámbar.

\section{Aspectos geológicos}

La complejidad estructural del entorno geológico en el que se ubican los yacimientos ambarígenos de Peñacerrada, hace necesario el desarrollo de un denso protocolo de actuación e implementación de numerosas técnicas geológicas, de cara a la consecución de dos objetivos: la comprensión y plasmación cartográfica de las capas portadoras de ámbar y el conocimiento de la vida diagenética de los yacimientos.

Ambos objetivos son fundamentales de cara a la toma de decisiones y a la adecuada gestión de éstos. El primero de ellos nos permitirá dimensionar objetivamente los recursos existentes, y proceder a su protección física y jurídica. Sólo desde el conocimiento estricto de su distribución, se podrá proceder al diseño de los adecuados proyectos de extracción y conservación.

El segundo objetivo aportará datos técnicos indispensables para la comprensión del ámbar alavés, tales como su estado de madurez, naturaleza y origen. Todos ellos, datos fundamentales de cara a la correcta interpretación y posicionamiento de los resultados procedentes del resto de las áreas de trabajo que conforman el proyecto Ámbar 2000.

\section{Aspectos patrimoniales}

Las colecciones procedentes de los trabajos en el yacimiento de Peñacerrada han aportado ya cientos de miles de registros y exigen, prácticamente desde su inicio, un posicionamiento profesional estricto. El peso específico de las mismas, desde el punto de vista científico, y la enorme capacidad de proyección pública derivada de su valor patrimonial y cultural, suponen un auténtico reto, tanto técnico como ad- 


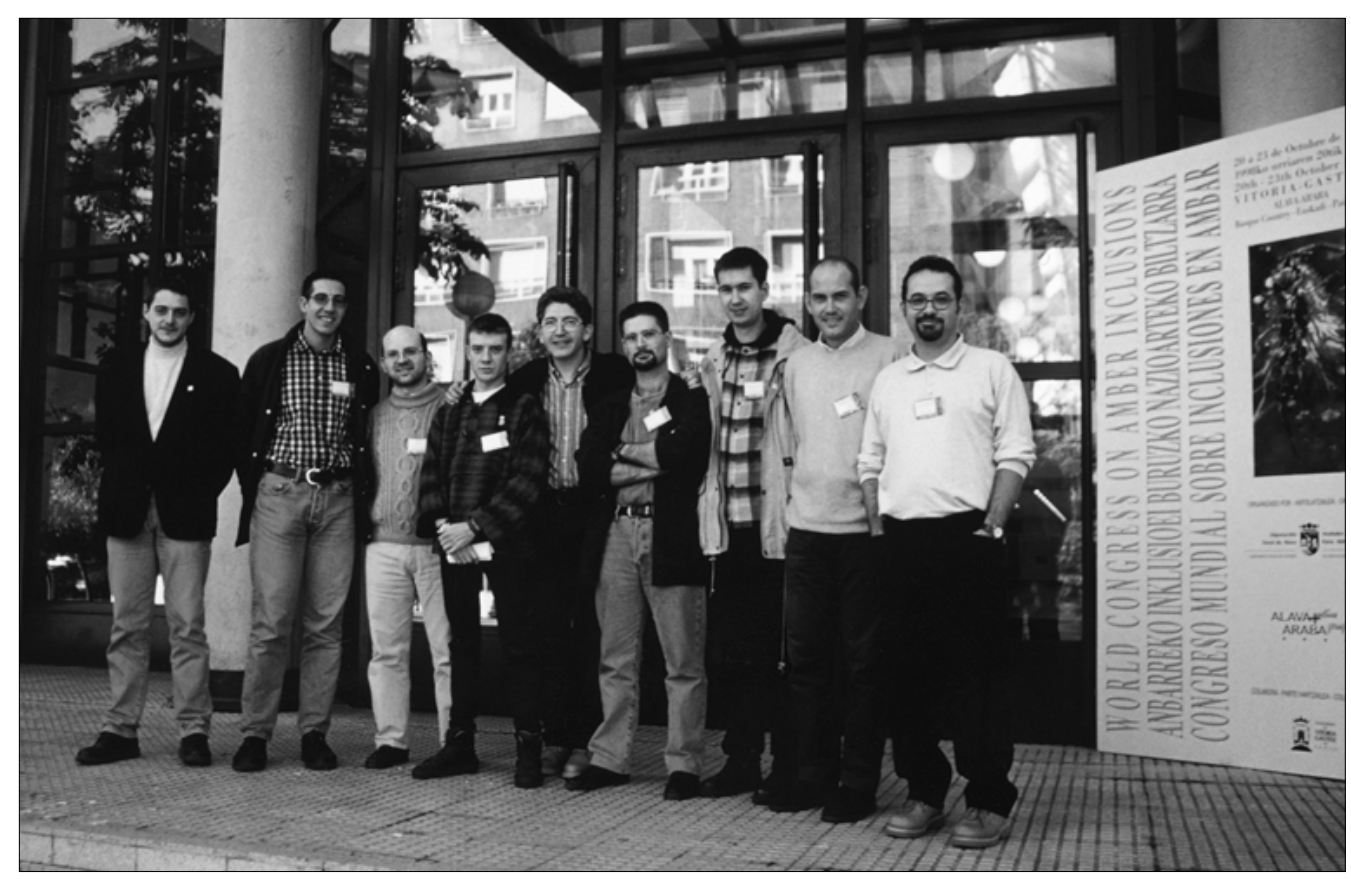

7. Equipo investigador en el palacio de Congresos Europa. De izquierda a derecha: Rafael López, descubridor y ahora preparador en el museo; Eduardo Barrón, paleobotánico y autor de las primeras dataciones del yacimiento; Carmelo Corral, paleontólogo conservador del museo; Rubén Cerdán, físico del equipo; Jesús Alonso, director del museo; Vicente Ortuño, paleontólogo, estudia todos los grupos de insectos salvo dípteros e himenópteros; Enrique Peñalver, de la Universidad de Valencia; Xavier Martínez Delclós, de la Universidad de Barcelona, junto con Peñalver estudian los heminópteros; Antonio Arillo, de la Universidad Complutense de Madrid, estudia los dípteros

ministrativo, al que solamente podemos dar una respuesta adecuada.

La categoría de "bien mueble" de las piezas de ámbar, al amparo de la Ley de Patrimonio Cultural Vasco, así como la misma praxis museológica, exigen, entre otras cosas, la correcta catalogación de las mismas, así como el desarrollo de todas aquellas labores encaminadas a su adecuado tratamiento y conservación.

Se ha procedido a la definición técnica de los protocolos necesarios para la correcta preparación de las muestras de ámbar; a la definición y creación de las aplicaciones informáticas necesarias para la catalogación y gestión de las colecciones; y a la dotación de los recursos materiales y humanos necesarios para abordar el cúmulo de tareas relativas al conocimiento del estado de conservación de las colecciones, la detección de problemas de deterioro, su diagnóstico y la aplicación de medidas paliativas.
Desde aquella primavera de 1995, han transcurrido cuatro años de intenso trabajo. Los primeros resultados han comenzado a fluir ya hacia la comunidad científica durante estos primeros meses del año. Deseamos que este flujo de información relativo al conocimiento de la vida que nos precedió, no tenga fin.

Es el momento de proceder. No hemos hecho otra cosa que establecer los cauces a través de los cuales ha de fluir el enorme volumen de información contenido en tan singular yacimiento. Los equipos responsables de abordar el cúmulo de tareas propuestas y por definir deberán colmar esos cauces.

Las preguntas han comenzado a formularse. Aguardaremos atentamente las primeras respuestas. 